\title{
Chronic rhinosinusitis in HIV- infected patients: radiological and clinical evaluation
}

\section{Ivan Dieb Miziara ${ }^{1}$, Bernardo Cunba Araujo Filbo', Rodrigo Cataldo de La Cortina ${ }^{3}$, Fabrício $R$. Romano ${ }^{4}$, Adriana S. Lima}

Key words: rhinosinusitis, HIV, AIDS, tomography computerized.

\section{Summary}

T he advent of protease inhibitors, which enhances the survival rate of HIV-infected individuals, leads patients to search for otorhinolaryngologists, as $40-70 \%$ of them may present some sort of otorhinolaryngological disorder. Aim: We aimed at comparing the CT scan findings and the nasosinusal complaints of HIV-infected and AIDS patients with clinical diagnosis of chronic rhinosinusitis. The literature on the subject is revised and discussed. Study design: clinical prospective with transversal cohort. Material and Methods: Prospectively, 39 patients with chronic rhinosinusitis, in use of antiretroviral therapy, were included in the present study and divided into two groups: patients with diagnosis of AIDS (group I) and those infected by HIV (group II). Clinical and laboratorial assessments, with CD4+ cell count and CT evaluation, were performed and compared among groups I and II. Results: Group I and II presented mean CD4+ cell count of 118 cells/10-91 and 377 cells/10-91, respectively. Comparison of the tomographic findings by the Lund-Mackay staging system presented a score of 12 for group I and 5.63 (pd"0.001) for group II. Fever and postnasal discharge were more prevalent in group I (pd"0.001). Conclusions: In our Service, prevalence of chronic rhinosinusitis in HIVinfected patients was $12 \%$. AIDS patients had a higher incidence of fever and postnasal discharge than those of group II. Moreover, extensive radiological findings were prevalent in patients with AIDS (group I) than in HIVinfected individuals (group II).

${ }^{1}$ Ph.D. in Otorhinolaryngology, Medical School, USP, Technical Director of Health Center.

${ }^{2}$ Otorhinolaryngologist, Specialist of Otorhinolaryngology, SBORL, Ph.D. studies under course, Division of Clinical Otorhinolaryngology, FMUSP. ${ }^{3}$ Ph.D., FMUSP, Otorhinolaryngologist. ${ }^{4} \mathrm{Ph} . \mathrm{D}$., FMUSP, Otorhinolaryngologist. 'Ph.D., FMUSP, Otorhinolaryngologist. Study carried out the Division of Clinical Otorhinolaryngology, Department of Otorhinolaryngology and Ophthalmology, Medical School, University of Sao Paulo. Address correspondence to: Bernardo Cunha Araujo Filho - Rua Oscar Freire 1799 ap. 302 Pinheiros Sao Paulo SP 05403-009. Tel: (55 11) 8319-4444 - E-mail: bcaf@terra.com.br Article submited on March 08, 2005. Article accepted on September 16, 2005. 


\section{INTRODUCTION}

The human immunodeficiency virus (HIV) has been widely studied and researched in the last two decades. The advent of protease inhibitors, which improves survival and quality of life of patients, has increased the number of asymptomatic HIV-infected individuals worldwide ${ }^{1,2}$. As a consequence, many of these patients have visited otorhinolaryngologists, since $40-70 \%$ of them may present some sort of otorhinolaryngological disorder ${ }^{2,3}$.

Chronic rhinosinusitis is the most common affection among HIV-infected patients, particularly those with advanced immunosuppression ${ }^{1,4}$. Prevalence of this disease in these individuals varied from $10 \%$ to $68 \%$, as reported in the literature ${ }^{1,2,4,5}$.

On the other hand, rate of lymphocyte population, specifically $\mathrm{CD} 4^{+}$lymphocytes, is considered a useful mean to assess the immunological response, which is directly related to severity and chronicity of rhinosinusitis of patients with low levels of $\mathrm{CD}^{+}{ }^{+}$Tlymphocytes ${ }^{4}$.

In order to assess patients with chronic rhinosinusitis, anamnesis plus radiological and endoscopic procedures are necessary. Computerized tomography of the paranasal sinuses yields a focused evaluation, as it quantifies extension of the sinunasal process. Lund-Mackay radiological classification system for rhinosinusitis is an easy and objective method in routine clinical practice ${ }^{6}$.

Our goal is to compare tomographic findings with the nasosinusal symptomatology among HIV-positive patients (with or without AIDS) with clinical diagnosis of chronic rhinosinusitis. The literature is also revised and discussed.

\section{MATERIAL AND METHOD}

The Otorhinolaryngology Ambulatory of Hospital das Clínicas, Medical School, University of Sao Paulo (HCFMUSP) admitted 314 seropositive patients with acquired immunodeficiency syndrome and general otorhinolaryngological complaints from July 1995 to November 2002. Prospectively, out of these patients, 39 presented chronic rhinosinusitis and were non-responsive to routine clinical treatments. All patients were receiving antiretroviral therapy and had been previously treated with oral antibiotics for sinusitis by their general practitioners.

Patients were submitted to anamnesis and complete otorhinolaryngological exam. Laboratorial assessment with $\mathrm{CD}^{+}$cell count was performed at first consultation. Computerized tomography (CT) of paranasal sinuses was performed at axial and coronal sections a week after the first consultation. Extension and severity of rhinosinusitis were radiologically graded according to Lund and Mackay criteria, suggested by the rhinosinusitis taskforce of the American Academy of Otorhinolaryngology ${ }^{6}$ (Table 1).
Patients were divided into two groups, according to presence of AIDS (group I, n=12) or HIV-infection only (group II, $\mathrm{n}=27$ ), following the CDC criteria (1993) ${ }^{7}$. Averages of $\mathrm{CD}^{+}$cells were compared in both groups. In addition, the most prevalent nasosinusal symptoms were also compared, while the tomographic findings were graded by Lund and Mackay system.

All data collected were statistically analyzed according to chi-square test (Fisher's precise test) and to Mann-Whitney U-Test.

All patients signed an informed consent term to participate in the study, which was approved by the Committee of Ethics of the Division of Clinical Otorhinolaryngology, HCFMUSP.

\section{RESULTS}

The prevalence of chronic rhinosinusitis in our series was of $12 \%$ - 39 patients non-responsive to routine clinical treatment among 314 seropositive patients with general otorhinolaryngological complaints.

Out of 39 selected patients, 12 (31\%) were diagnosed with AIDS and the others (27) were HIV-infected only. Age ranged from 5 to 62 years, mean of 32 . Thirtyone individuals were men (79.4\%).

The most frequent cause of HIV transmission was sexual intercourse (65.5\%), followed by intravenous drug use (17.2\%), blood transfusion (10.3\%) and vertical transmission (7\%).

Group I patients had an average $\mathrm{CD}^{+}$cell count of $118 / 10^{-9} 1$, while group II presented an average of 377 cells/ $10^{-9} 1$. The difference was statistically significant $(\mathrm{p}<$ 0.005).

Comparison of tomographic findings (Tables 2a, 2b and 3) demonstrated that group I patients presented a mean score of 12 (standard deviation: 3.33), while group II was of 5.63 (standard deviation: 3.13). A significantly statistical difference was observed between both groups $(p<0.001)$. Presence of a pansinusal mucous layer was observed in all images of group I patients. Presence of

Table 1. Radiological grading of the sinusal system proposed by Lund and Mackay.

\begin{tabular}{l}
\hline Sinusal system Left \\
Maxillary \\
Anterior ethmoid \\
Posterior ethmoid \\
Sphenoid \\
Frontal \\
Osteomeatal complex \\
Total score for each side \\
Scores: Sinuses $0=$ no alterations, $1=$ partial opacification, $2=$ total \\
opacification \\
Osteomeatal complex: $0=$ not occluded, $2=$ obstructed
\end{tabular}


pansinusal opacification was observed in 4 patients of group I, all presenting CD4+ levels below 80 cells/ $10^{-9} 1$. The maxillary sinus was prevalently the most affected. All patients had tomographic alterations of the maxillary sinus (100\%).

Table 2a. Radiological grading of the sinusal system proposed by Lund and Mackay in each side of Group I.

\begin{tabular}{ccc}
\hline Patients & Left & Right \\
\hline 1 & 9 & 2 \\
2 & 4 & 8 \\
3 & 7 & 6 \\
4 & 3 & 8 \\
5 & 7 & 0 \\
6 & 2 & 8 \\
7 & 10 & 1 \\
8 & 10 & 8 \\
9 & 6 & 7 \\
10 & 8 & 0 \\
11 & 7 & 5 \\
12 & 10 & 8 \\
\hline Total & 83 & 61 \\
\hline
\end{tabular}

Table 2b. Radiological grading of the sinusal system proposed by Lund and Mackay in each side of Group II.

\begin{tabular}{|c|c|c|}
\hline Patients & Left & Right \\
\hline 13 & 4 & 2 \\
\hline 14 & 0 & 5 \\
\hline 15 & 6 & 0 \\
\hline 16 & 3 & 0 \\
\hline 17 & 0 & 4 \\
\hline 18 & 7 & 2 \\
\hline 19 & 0 & 2 \\
\hline 20 & 2 & 4 \\
\hline 21 & 8 & 0 \\
\hline 22 & 4 & 4 \\
\hline 23 & 5 & 1 \\
\hline 24 & 4 & 2 \\
\hline 25 & 6 & 2 \\
\hline 26 & 8 & 4 \\
\hline 27 & 2 & 4 \\
\hline 28 & 8 & 2 \\
\hline 29 & 6 & 1 \\
\hline 30 & 3 & 0 \\
\hline 31 & 0 & 2 \\
\hline 32 & 0 & 4 \\
\hline 33 & 0 & 3 \\
\hline 34 & 2 & 1 \\
\hline 35 & 4 & 2 \\
\hline 36 & 0 & 4 \\
\hline 37 & 1 & 3 \\
\hline 38 & 2 & 2 \\
\hline 39 & 4 & 3 \\
\hline Total & 89 & 63 \\
\hline
\end{tabular}

Assessment of nasosinusal symptoms among the groups (Table 4) showed significant differences only for fever and postnasal secretion $(\mathrm{p}<0.001)$.

\section{DISCUSSION}

Chronic rhinosinusitis has been reported as a common disease in HIV-infected patients ${ }^{4,5}$. However, its prevalence has shown to be varied in many studies, which is probably due to different methods and methodologies used to diagnose rhinosinusitis ${ }^{4,8}$. Garcia-Rodrigues et al. ${ }^{4}$ reported a prevalence of $35 \%$, taking into account the clinical symptomatology, endoscopic exam and computerized tomography in the diagnosis of rhinosinusitis. Tarp et al. ${ }^{8}$, using magnetic resonance imaging, observed a prevalence of $54.3 \%$. Porter et al. ${ }^{1}$ presented $70 \%$ prevalence as a result of a survey on nasosinusal symptoms. In our study, we found a prevalence of $12 \%$ among 314 seropositive patients with general otorhinolaryngological complaints who were referred to our otorhinolaryngology ambulatory. The low prevalence (12\%) of these complaints in our case series may be due to the fact that acute conditions were initially treated by infectologists or general physicians, and only the patients who were not responsive to initial treatment were referred to us.

Regarding the symptomatology, our patients presented the same signs and symptoms in both groups (with and without AIDS), similarly to the population in general. The most common findings were purulent rhinorrhea, nasal obstruction and headache, respectively, which is in accordance with Zurlo et al. .

Porter et al. ${ }^{1}$, when comparing seropositive patients - with or without AIDS -, also concluded that the symptoms and severity of rhinosinusitis were similar in both groups. However, we observed in our study that, from radiologically analyses, rhinosinusitis was more severe in AIDS patients, who presented extensive nasosinusal disease.

Our findings are consistent with those of Tarp et al. ${ }^{8}$, whose study infers that AIDS patients have more significant pathological alterations than HIV-infected individuals. In addition, our study agrees with Small et al. ${ }^{10}$, which compared groups of seropositive patients and AIDS patients, observing higher IgE levels in the latter. In fact, they attribute to atopy and allergic reaction the base of rhinosinusitis development in these patients ${ }^{10}$.

Relative to AIDS, fever had high incidence in our study (66.6\%) (Table 4), which in immunodepressive patients may sign an unspecific response to the presence of infection, justifying its great significance. Differently, posterior rhinorrhea can be indicative of higher severity of the disease in AIDS patients.

Difference in $\mathrm{CD}^{+}$cell count in both groups was statistically significant. Average levels observed in both groups were lower than 200 cells $/ 10^{-9} 1$, indicating highly severe 
immunosuppression, as well as greater proneness to chronification and severe rhinosinusitis ${ }^{3,4,11,12}$. Inversely, in Porter et al. ${ }^{1}$ and Tarp et al. ${ }^{8}$ studies, CD4+ levels were not significantly lower in patients with great nasosinusal alterations.

Regarding the radiological findings, the use of LundMackay system demonstrated practical application and adequate interpretation power, as suggested by its precursors ${ }^{6}$. AIDS patients presented higher average score of paranasal sinus affection than HIV-infected individuals.

Concomitantly, it is important to emphasize that the $\mathrm{CD}^{+}$levels observed reveal a predictive tendency to larger tomographic alterations proportionally to the immunosuppression grade, although this study's casuistic may have limited significance due to the reduced number of patients. However, suspicion is based on the tomographic findings, which reveal larger pansinusal mucous layer in patients of group I. The other four patients with pansinusal opacification presented CD4 ${ }^{+}$levels below 80 cells/ $10^{-9} 1$. These data are in accordance with those reported by Godofsky et al. ${ }^{13}$, who previously demonstrated an inverse relation between $\mathrm{CD}^{+}$cell count and number of affected sinuses.

Involvement of maxillary sinuses is common among HIV-infected population with rhinosinusitis ${ }^{2,4,8,14-16}$. In our series, the most affected sinus in both groups was the maxillary sinus (100\%).

Tarp et $a .^{8}$ used magnetic resonance to diagnose rhinosinusitis in HIV-infected patients, disregarding the clinical diagnosis. For some authors, tomography is a secondary exam in infected patients, which is performed only in cases where the endoscopic exam proved to be ineffective to diagnose rhinosinusitis ${ }^{4}$. However, chronic rhinosinusitis in some cases may be "silent", with no symptoms, but presenting important radiological alterations in the computerized tomography ${ }^{6,13}$. Moreover, in our study, similarity of symptoms was also observed in both groups. Therefore, we partially disagree with these authors, as we believe that imaging provides us with essential information concerning nasosinusal disease and its intensity in immunodepressed patients.

Finally, we believe that tomography is an extremely important exam in the assessment of positive HIV-patients, particularly in those with low levels of $\mathrm{T} \mathrm{CD} 4^{+}$lymphocytes, which present higher severity of nasosinusal disease. Moreover, this exam is useful both to exclude fungi infection and to improve presurgical plan, which was verified in our study and of other authors ${ }^{6,13,17}$. In our opinion, the use of radiological methods associated with anamnesis and nasofibroscopy would be a good choice in daily clinical practice.

\section{CONCLUSION}

- Prevalence of chronic rhinosinusitis in HIV-infected patients referred to our otorhinolaryngology ambulatory was of $12 \%$.

- Incidence of fever and posterior rhinorrhea was statistically higher in AIDS patients (group I) than in seropositive ones (group II).

Table 3. Scores of groups I and II according to Lund and Mackay radiological scale.

\begin{tabular}{|c|c|c|c|c|}
\hline \multicolumn{5}{|c|}{ Group } \\
\hline & AIDS $(n=12)$ & HIV Positive $(n=27)$ & $P$ * & Total \\
\hline Mean score left side & $6.92 \pm 2.75$ & $3.15 \pm 2.58$ & 0.024 & $4.31 \pm 3.14$ \\
\hline Mean score right side & $5.08 \pm 3.37$ & $2.48 \pm 1.81$ & 0.001 & $3.28 \pm 2.65$ \\
\hline Mean score total & $12.0 \pm 3.33$ & $5.63 \pm 3.13$ & $<0.001$ & $17.59 \pm 4.33$ \\
\hline
\end{tabular}

* Mann-Whitney U-Test

Table 4. Prevalence of symptoms among patients in groups I and II.

\begin{tabular}{|c|c|c|c|}
\hline \multicolumn{4}{|c|}{ Group } \\
\hline SINTOMAS & Group I AIDS $(n=12)$ & Group II HIV Positive $(n=27)$ & ${ }^{\star} \mathrm{P}$ \\
\hline Rhinorrhea & $8(66.6 \%)$ & $14(51.9 \%)$ & 0.49 \\
\hline Nasal obstruction & $10(83.3 \%)$ & $13(48.1 \%)$ & 0.07 \\
\hline Headache & $10(83.3 \%)$ & $13(48.1 \%)$ & 0.07 \\
\hline Facial ache & $6(50 \%)$ & $5(18.5 \%)$ & 0.06 \\
\hline Anosmia & $4(33.3 \%)$ & $4(14.8 \%)$ & 0.22 \\
\hline Fetid smell & 5 (41.6\%) & $4(14.8 \%)$ & 0.1 \\
\hline Cough & $3(25 \%)$ & $3(11.1 \%)$ & 0.34 \\
\hline Postnasal secretion & $10(83.3 \%)$ & $3(11.1 \%)$ & $<0.001$ \\
\hline Epistaxis & $1(8.3 \%)$ & $1(3.7 \%)$ & 0.56 \\
\hline
\end{tabular}

Brazilian Journal of Otorhinolaryngology 71 (5) Part 1 September/October 2005

http://www.rborl.org.br / e-mail: revista@aborlccf.org.br 
- AIDS patients presented more extensive nasosinusal alterations in computerized tomography assessment than HIV-positive patients.

\section{REFERENCES}

1. Porter JP, Patel AA, Dewey CM, Stewart MG. Prevalence of Sinonasal Symptoms in Patients with HIV Infection. Am J Rhinol 1999; 13(3): 203-8.

2. Murphy C, Davidson TM, Jellison W, Austin S, et al. Sinonasal Disease and Olfactory Impairment in HIV Disease: Endoscopic Sinus Surgery and Outcome Measures. The Laryngoscope 2000; 110 (Oct): 1707-10

3. Belafsky PC, Amedee R, Moore B, Kissinger PJ. The Association Between Sinusitis and Survival Among Individuals Infected with the Human Immunodeficiency Virus. American Journal of Rhinology 2001; 15 (5): 343-5.

4. Garcia-Rodriguez JF, Corominas M, Fernandez-Viladrich P, Monfort JL, Dicenta M. Rhinosinusitis and Atopy in Patients Infected with HIV. The Laryngoscope 1999; 109(6): 939-44.

5. Tami TA. The Management of Sinusitis in Patients Infected with the Human Immunodeficiency Virus (HIV). Ear Nose Throat J 1995; 74(5): 360-3.

6. Lund V, Kenndy DW. Staging for Rhinosinusitis. OtolaryngologyHead and Neck Surgery 1997; 117(3pt 2): 35-40.

7. Hudeleringh RJ. Recurrent maxillary sinusitis on AIDS patients. In: Proceedings of the Ivth International Conference on AIDS. The Scientific and Social Challenge. Abstracts. International Development Research Center, Ottawa 1989; p.255.
8. Tarp B, Fiirgaard B, Moller J, Hilberg O, et al. The Ocurrence of Sinusitis in HIV-Infected Patients with Fever. Rhinology 2001; 39: 136-41.

9. Zurlo JJ, Feuerstein IM, Lebovics R, Lane HC. Sinusitis in HIV-1 Infection. Am J Med 1992; 93(2): 157-62.

10. Small CB, Kaufman A, Armenaka M, Rosenstreich DL. Sinusitis and Atopy in Human Immunodeficiency Virus Infection. The Journal of Infectious Disease 1993; 167: 283-90.

11. Meiteles LZ, Lucente FE. Sinus and Manifestations of the Acquired Immunodeficienty Syndrome. Ear, Nose and Throat 1990; 69: 454-9.

12. Upadhyay S, Marks SC, Arden RL, Crane LR, Cohn AM. Bacteriology of Sinusitis in Human Immunodeficiency Virus-Positive Patients: Implications for Management. Laryngoscope 1995; 105 (10): 1058-60.

13. Godofsky EW, Zinreich J, Armstrong M, Leslie JM, Weikel CS. Sinusitis in HIV-Infected Patients: A Clinical and Radiographic Review. Am J Med 1992; 93(2): 163-70.

14. Rubin JS, Honinberg R. Sinusitis in Patients with the acquired immunodeficiency syndrome. Ear, Nose and Throat Journal 1990; 69: 460-3.

15. Mofenson LM, Korelitz J, Pelton S, Moye J Jr, Nugent R, Bethel J. Sinusitis in Children Infected with Human Immunodeficiency Virus: Clinical Characteristics, Risk Factors, and Prophylaxis. National Institute of Child Health and Human Development Intravenous Immunoglobulin Clinical Trial Study Group. Clin Infect Dis 1995; 21(5): 1175-81.

16. Stuck M, Hachler I, Luthy R, Ruef C. Sinusitis in HIV Infection. Dtsch Med Wochenschr 1994; 119(51-52): 1759-65.

17. Spech TJ, Rehm, SJ, Longworth DL, Keys TF, McHenry MC Frequency of sinusitis in AIDS patients. In: Proceedings of the IVth International Conference on AIDS. 1988: Stockhol International Affairs, Stockholm; Abstract 7.088. 